\title{
As Formulações - Fonte do Direito Administrativo
}

\author{
Luiz Rodrigues \\ Consultor Jurídico do DASP
}

As Formulações, com a força obrigatória que têm, por emanarem do Órgão Central do Sistema de Pessoal (SIPEC), devem ser aplicadas a todos os casos idênticos. Pode-se afirmar, em decorrência disso, que constituem fonte do Direito Administrativo, no que diz respeito ao regime jurídico do servidor público civil. Criam elas direitos subjetivos.

O Departamento Administrativo do Pessoal Civil (DASP) é o Orgão Central do Sistema de Pessoal; compete-Ihe, em face do estabelecido no artigo 115 do Decreto-lei $n .^{\circ} 200$, de 1967, o estudo, proposições de diretrizes, coordenação, supervisão e Controle de assuntos concernentes à Administração do Pessoal Civil da União.

Assim, em decorrência do direito positivo brasileiro, cabe-lhe orientar, coordenar e controlar a aplicação dos diplomas legais e regulamentares, e também a jurisprudência, vinculados com o regime jurídico dos servidores federais da Administracão Direta e das Autarquias.

Sendo, como é, um Órgão Central de um Sistema não the é específica a tarefa de execução, mas sim de orientação normativa, disciplinando a solução que deva ser dada aos problemas ligados ao regime jurídico dos servidores, nos Órgăos Setoriais do mesmo Sistema.

Compete a esses Órgãos de periferia do Sistema a execução, a decisão dos casos concretos que aparecerem nas suas áreas de atividade, o que deverá verificar-se em estrita obser- 
vância à orientação normativa ditada pelo Órgão Central DASP. Esta unidade administrativa zela, a todo instante, pelo fiel cumprimento daquela orientação, ao desenvolver o seu trabalho de supervisão e controle dos atos praticados pelos dirigentes dos Órgãos Setoriais.

Os pronunciamentos do DASP e da Consultoria-Geral da República, órgão de cúpula na atividade juridica do Poder Executivo, por possuírem caráter normativo, têm aplicação a outras situações que apresentem igualdade, nos pressupostos fáticos e jurídicos, com aquela originária do parecer emitido e no qual se fixou o entendimento que serviu de fundamento à Formulação.

A atividade de interpretar os textos legais e regulamentares, no que concerne ao regime de pessoal, é específica do Órgão Central do Sistema e, quando muito, num caso de alta indagação jurídica, da Consultoria-Geral da República. Em assim ocorrendo, os Órgãos Setoriais liberados estão daquela tarefa, cabendo-Ihes apenas examinar os pontos de contacto, a coincidência dos pressupostos fáticos e jurídicos e aplicar a orientação normativa fixada.

O Orgão Central do Sistema, nesse seu papel de intérprete da lei administrativa, pode buscar fórmulas impessoais, diretrizes, constituindo as Formulações, não só como resultado do exame de casos concretos a ele submetidos, como também em decorrência de um estudo antecipado de um diploma legal, referente ao funcionalismo, que deva ter aplicação uniforme em todos os setores da Administração Direta e Autárquica.

As Formulações retratam a orientação necessária, o devido alcance de uma norma jurídico-administrativa, a forma de proceder da Administração para determinadas situações jurídicas e, diante delas, nenhuma tarefa maior surge para os Orgãos Setoriais, senão enquadrar as consultas e reivindicações nas fórmulas preestabelecidas.

O efeito imediato das Formulações é o desemperramento da máquina administrativa, com a descentralização do processo decisório. Evitar-se-á, como se tem evitado, a perda de tempo por parte dos agentes administrativos, pertencentes ao Quadro de um Órgão Setorial, na solução de problemas que se lhes deparam e também se eliminarão as consultas sucessivas, sobre um mesmo assunto, ao Órgão Central do Sistema. 
Das Formulações resultará ainda a uniformidade de solução dos casos que digam de perto ao regime jurídico do servidor público e, conseqüentemente, a maior estabilidade da Administração Pública, no que concerne à sua vinculação com os agentes que a servem, e o perfeito conhecimento, por parte destes, dos seus direitos e obrigações, enquanto integrantes forem dos quadros do funcionalismo público federal.

Outro aspecto importante das Formulações, em face da dificuldade de consultas a pareceres e instruções normativas em Diários Oficiais, é trazer aqueles que peticionam no Judiciário ou junto às repartições públicas bem informados do procedimento administrativo em relação ao regime jurídico do servidor público federal.

As Formulações são proposições impessoais, autônomas, genéricas e sucintas que retratam o entendimento predominante na esfera do Poder Executivo a respeito de uma determinada situação jurídico-administrativa, concernente ao regime do servidor público pertencente à Administração Direta ou Autárquica.

As Formulações não são sempre conseqüentes da interpretação de um texto de lei ou de reiteradas decisões a respeito de uma determinada relação jurídico-administrativa expressa em diploma legal; muitas vezes espelham um procedimento administrativo a ser adotado e que não tem fulcro em texto de lei ou em norma regulamentar expressos, mas que está inserido num contexto, num enquadramento sistemático e político, adotado pela Administração, pois toda a atividade administrativa pressupõe sempre fim legal e de interesse imediato para a coletividade.

A Administração é máquina em dinâmica constante e, na consecução de suas atividades, tem que ter pronta solução para todos os problemas que se lhe deparam; embora haja multiplicidade de leis e decretos referentes ao regime do servidor público, muitas situações ainda não foram disciplinadas em diplomas legais ou regulamentares, e, preenchendo as omissões, surgem pronunciamentos administrativos pautando a ação da Administração, e, nesse passo, as Formulações retratam aquela forma de proceder que deverá ser obrigatoriamente observada pelos servidores públicos federais e autárquicos, não só na consecução de suas atividades, mas também em relação às suas próprias reivindicações. 
O que a lei administrativa não estipula expressamente não se presume que seja facultado, e objetivando essas circunstâncias, as Formulações vêm, muitas vezes, uniformizar a concessão ou a negativa de benefícios pleiteados por agentes administrativos.

A Formulação constitui meio hábil para aplicação do regime jurídico dos servidores públicos, e basta, ao ser examinado um caso concreto, a citação do número correspondente a ela, para dispensar argumentações complementares de direito.

As conclusões insertas nos pronunciamentos que deram origem às Formulações têm força obrigatória, pois visam a uniformizar as decisões dos Órgãos Setoriais do Sistema, os quais possuem, como encargo precípuo, aplicar as normas disciplinadoras do regime jurídico do servidor público.

São dotadas de força coativa em decorrência da competência específica do Órgão de onde são emanadas e da posição desse na composição do Sistema. A sua inobservância redunda na instabilidade administrativa decorrente da desuniformidade de tratamento, justificando sempre a interferência do Órgão Central no sentido de anular atos praticados com infringência aos preceitos contidos nas Formulações, porquanto essas representam o alcance real da norma legal ou regulamentar, em face do caso concreto, ou os procedimentos ideais a serem adotados pela Administração, os quais por sua vez não se dissociam dos princípios informadores e interpretativos do Direito Administrativo.

Na conformidade do Decreto-lei n. 200 , de 1967, os órgãos que compõem um Sistema, que tem a seu cargo a consecução de atividade-auxiliar ou atividade-meio, se vinculam no sentido de uniformização de decisões e, para isso, os órgãos executores, que são os Setoriais, recebem do Órgão Central a orientação normativa, a supervisão e o controle dos seus atos, isto
objetivando sempre o fiel cumprimento das Instruções Normati-
vas e das. Formula vas e das Formulações.

Esses órgãos setoriais não perdem a sua posição hierárquica na estrutura da unidade administrativa a que pertencem. não obstante estarem vinculados tecnicamente ao Órgão Central. No entanto, só devem observância à orientação do Órgão R. Serv. Púb!, Brasília, 108 (2): mai./ago. 1973 
Central, dada a força obrigatória da mesma, impedindo, assim, a desigualdade de decisões na aplicação do regime jurídico do servidor público.

$\mathrm{Na}$ Formulação, quando concretizada através de publicação, o preceito nela contido tem aplicação uniforme a todos os casos que com ela guardem harmonia, nos seus pressupostos e alcance.

Em decorrência da posição estrutural do órgão de onde emana a Formulação, da competência específica do mesmo e da força obrigatória intrínseca do preceito nela contido, será ela aplicada, como se afirmou acima, a todas as situações funcionais idênticas. Conseqüentemente, pode-se concluir que as Formulações criam direitos subjetivos para todos os agentes que estiverem em igualdade de condições, isto é, apresentarem os mesmos pressupostos, de fato e de direito, que serviram de alicerce à fixação da regra.

As Formulações, embora genéricas e impessoais, devem ser sucintas, claras e precisas, abrangendo tudo aquilo que se pretende afirmar; não podem nunca ser imprecisas, ensejando extensões descabidas.

Criando, como se disse, direitos subjetivos, forçoso é concluir que constituem as Formulações uma fonte do Direito Administrativo, no que concerne ao regime do pessoal público civil da Administração Direta e das Autarquias.

A obrigatoriedade de observância das Formulações, na esfera do Poder Executivo, dá-lhes uma característica bem diferente das Súmulas do Supremo Tribunal Federal, no que diz respeito às decisões dos órgãos integrantes do Poder Judiciário, muito embora o objetivo de ambas seja o mesmo.

Com efeito, enquanto a palavra subordinação é estranha aos Órgãos da Justiça, vez que os juízes a ninguém estão subordinados senão à lei, tal não se verifica na área do Poder Executivo. Quanto a este Poder, a regra é prevalência do princípio hierárquico do qual decorre a subordinação. Conforme se asseverou, não há falar em subiordinação entre os Órgãos Centrais e Setoriais, já que estes ficam apenas vinculados à orientação normativa daqueles. É, porém, indiscutivel que tal vinculação redunda numa forma especial de subordinação. 
De fato, há conveniência, mas não obrigatoriedade, no seguimento dos preceitos Sumulares pelos demais Órgãos que compõem o Podèr Judiciário, porquanto inexiste, dentro desse Poder, a subordinação hierárquica ou mesmo vinculações de órgãos a outros.

A Súmula, no Supremo Tribunal Federal, disciplina as suas decisões posteriores, mas não obriga nem aquela Colenda Corte, nem os demais Órgãos do Judiciário. O mesmo não se pode afirmar quanto às Formulações, pois estas têm força coativa logicamente dentro do Poder Executivo, na área específica dos órgãos que estão integrados no SIPEC e para disciplinação das decisões atinentes à clientela que lhes é própria.

As Formulações não são inalteráveis, acompanham a evolução da política administrativa e terão que adaptar-se aos novos Planos Técnicos da Administração. Entretanto, enquanto não forem modificadas pelo Órgão Central devem merecer aplicação uniforme. Somente podem ser alteradas em decorrência de outro pronunciamento do Órgão Central ou da Consultoria-Geral da República, no qual inserta esteja uma conclusão mais aprimorada e que reflita perfeitamente o alcance social da norma legal ou da justeza do procedimento administrativo.

Evoluem, portanto, as Formulações, assim como ocorre com qualquer fonte do direito.

Não há necessidade de reiteradas decisões administrativas para consubstanciar uma Formulação. Basta um só pronunciamento do Orgão para bem fundamentá-la.

As Formulações constituem, como se disse, norma jurídica obrigatória; não são meramente programáticas. Têm como sujeito, ora ativo ora passivo, a Administração, exigindo e assumindo a obrigação do preceito que nela encerra.

Formulações, portanto, mercê de sua adoção obrigatória pelos Órgãos que integram o Sistema de Pessoal, são criadoras de direitos subjetivos e, por via de conseqüência, nova fonte do direito administrativo. 